Article

\title{
Aesthetics and Survival of Immediately Restored Implants in Partially Edentulous Anterior Maxillary Patients ${ }^{\dagger}$
}

\author{
Roni Kolerman ${ }^{1, *}$, Haim Tal ${ }^{1}$, Jose Luis Calvo Guirado ${ }^{2}$ (D), Eitan Barnea ${ }^{3}$, Liat Chaushu ${ }^{1}$, \\ Manar Abu Wasel ${ }^{4}$ and Joseph Nissan ${ }^{5}$ \\ 1 Department of Periodontology and Dental Implantology, The Maurice and Gabriela Goldschleger School of \\ Dental Medicine, Tel-Aviv University, Tel Aviv 69978, Israel; talhaim@post.tau.ac.il (H.T.); \\ Liat.natanel@gmail.com (L.C.) \\ 2 Oral Surgery and Implant Dentistry, Universidad Católica San Antonio de Murcia (UCAM), \\ 30107 Murcia, Spain, jlcalvo@ucam.edu \\ 3 Specialist in Oral Rehabilitation, Private Practice Tel-Aviv, Tel-Aviv 69978, Israel; eitanbarnea@gmail.com \\ 4 The Maurice and Gabriela Goldschleger School of Dental Medicine, Tel-Aviv University, \\ Tel Aviv 69978, Israel; manara@mail.tau.ac.il \\ 5 Department of Oral Rehabilitation, The Maurice and Gabriela Goldschleger School of Dental Medicine, \\ Tel-Aviv University, Tel Aviv 69978, Israe; nissandr@gmail.com \\ * Correspondence: daniaron@netvision.net.il \\ + Running title: Immediate Restoration in the Anterior Maxilla.
}

Received: 18 November 2017; Accepted: 1 March 2018; Published: 5 March 2018

\begin{abstract}
This retrospective study was undertaken to determine survival rates and aesthetic outcomes of immediate placement of multiple implants at anterior maxilla sites. One hundred and eighteen implants placed in 39 patients ( 21 women and 18 men; average age 58.3 years) were immediately restored (24-72 $\mathrm{h}$ after placement). Aesthetic assessment, radiographic bone loss, and biological and prosthetic complications were evaluated. Data collection between 12 and 84 months (mean $32.2 \pm 18$ ) after final prosthetic installation revealed that no implants were lost, and that 106/118 (89.8\%) implants had no more than $1.5 \mathrm{~mm}$ of bone loss by the end of the first year and an additional $0.2 \mathrm{~mm}$ for each successive year. The marginal bone loss was higher for extractions due to periodontitis compared to extractions due to caries (mean mesial loss of $1.37 \mathrm{~mm}$ vs. $1.01 \mathrm{~mm}$, respectively, and mean distal loss of $1.37 \mathrm{~mm}$ and $0.99 \mathrm{~mm}$, respectively, $p=0.001$ ). The mesial papilla was present in 83/118 implants (70.3\%), while the distal papilla was present in 76/118 implants (64.4\%). The cervical metallic part of the abutment was exposed in 16/118 (13.5\%) implants. There was a higher ratio of recessions and missing papillae in patients in whom the extractions were performed due to periodontal reasons. Within the limitations of the present study, aesthetic and radiographic parameters support immediate restoration of partially edentulous maxillae.
\end{abstract}

Keywords: immediate restoration; aesthetic assessment; allograft

\section{Introduction}

Osseointegration has been redefined according to current patients' increasing demands for reduced treatment time, improved esthetics, and increased comfort. The immediate implant placement into fresh extraction sockets may attain implants survival rates similar to those of delayed placement with considerable shortening of the healing period, providing that primary stability had been achieved [1-6]. In addition to immediate implantation, the time gain has been further enhanced by reducing or even eliminating the load-free time following implant installation. Several researchers have demonstrated successful immediate loading in edentulous mandibles [7-10] and maxillae [11-14]. 
This has led to immediate single-tooth implant-retained provisional restoration [15-18]. However, it has been shown that the implant's esthetic outcome may be hampered by recessions of the marginal peri-implant mucosa [19-21]. The occurrence and degree of the marginal mucosal recession have been associated with several factors, including tissue biotype [22], connection of a temporary crown immediately after implant insertion [23,24], condition and width of the facial bone [25], orofacial position of the implant shoulder [26,27], and grafting of the facial peri-implant marginal defect with bone or bone replacement grafts $[28,29]$. Flap elevation that disrupts the vascular supply to the buccal bone, which is composed almost entirely of bundle bone, may be an important contributory mechanism in the etiology of buccal recession [30].

Adaptation of a temporary restoration contoured to mirror the removed tooth is intended to support the marginal gingiva by providing a platform to promote soft-tissue healing and protect the healing extraction socket [23]. Notably, immediate implantation and restoration without occlusion achieve a significantly higher implant survival rate compared with restoration with occlusion [14].

An ideal three-dimensional (3D) implant position within the bone contour and the dimensions of the buccal bone as well as the anatomic height of the interproximal bone are strongly associated with achievement of successful aesthetic results [26,31]. The height of the papilla next to dental implants is one of the main parameters that affects the aesthetic outcome of implant therapy [32,33]. Implant-to-soft tissue attachment lacks Sharpey's fibers, which, taken together with the fact that a previous interdental bone peak will resorb following extraction of teeth adjacent to implants, may be considered of utmost importance in the process of reduced papilla height between adjacent dental implants [34]. Interestingly, the same applies to papilla between an implant and a pontic and, to a lesser extent, to papilla between adjacent pontics [35].

It has been proposed that a minimal distance of $1.5 \mathrm{~mm}$ between a dental implant and an adjacent tooth is necessary to compensate for remodeling processes following the establishment of the biologic width [36,37]. If two dental implants are placed next to each other, an optimal distance of $3 \mathrm{~mm}$ between them was suggested to obtain a normal papilla [38].

Implant location relative to the bucco-oral and mesiodistal dimensions of the alveolar ridge is a factor that is thought to affect the degree of bone remodeling [39] and have an impact on the aesthetic outcome [40]. It has also been claimed that the buccal bone should measure at least $2 \mathrm{~mm}$ to avoid significant bone reduction after implant placement [41].

We are aware of only a few publications on a one-stage procedure aiming to achieve hard-tissue augmentation using the classic guided bone regeneration (GBR) technique and immediate non-functional loading of multiple implants in the maxillary esthetic zone. The objectives of this study were to evaluate the survival and success rates of implants placed immediately into extraction sockets in combination with GBR, and to provide detailed information about the predictability of objective aesthetic parameters, such as the presence or absence of papillae and the frequency of recessions.

\section{Materials and Methods}

\subsection{Patient Population}

Thirty-nine patients who were treated consecutively by the senior author (R.K.) during the years 2005-2012 comprised the study population. The sample size was not based on power considerations, as all available cases were included in this analysis. Treatment included maxillary multiple-tooth implants according to the concept of immediate nonfunctional loading. The Tel Aviv University Ethics Committee approved the study, and all patients signed an informed consent form permitting the use of their data in retrospect. 


\subsection{Patient Selection}

Inclusion criteria for patient selection were:

- need for the extraction of more than one tooth in the aesthetic zone of the upper jaw (incisors, lateral incisors, canine, premolars, and first molar)

- minimum age of 18 years

- good oral hygiene, defined as full mouth plaque score $\leq 25 \%$ [42]

- at least $5 \mathrm{~mm}$ of bone apical or palatal to the alveolus of the failing tooth to ensure primary implant stability of at least $30 \mathrm{Ncm}$

- at least partial integrity of the residual bone walls after extraction

Exclusion criteria were:

- heavy use of tobacco (more than 10 cigarettes a day)

- recent (previous six months) radiotherapy of the head and neck region or recent treatment with bisphosphonates

- active periodontal disease involving residual dentition

- mucosal diseases, such as lichen planus, in the areas to be treated

- poor oral hygiene or lack of compliance

- para-functional habits, such as bruxism

- uncontrolled diabetes

- acute infection (with the presence of pus and swelling) around the failing tooth

- failure to obtain primary stability of more than $30 \mathrm{Ncm}$ (Note: the site was augmented and closed for a two-stage procedure of the specific implant in these cases)

\subsection{Surgical Protocol}

A detailed pre-surgical evaluation that comprised a full-mouth periodontal chart and an occlusal analysis was carried out. Data on smoking habits, periodontal diagnosis, and reason for extraction were obtained and recorded prior to a decision of extraction and surgery. The cause-related therapy included oral hygiene instructions and scaling and root planning when indicated, followed by additional periodontal therapy aiming to reduce periodontal probing depth and bleeding upon probing. Periapical radiographs were obtained before (Figure 1) and immediately after implant placement, six months later, once yearly, and at the time of data collection (1-7 years after bridge installation). A preoperative computed tomogram (CT) was obtained to evaluate the height and width of the alveolar process. Special attention was given to the existence of any bone undercuts, the location of the roots to be extracted, the presence of periapical/peri radicular pathologies, and the location of the incisive foramen. Premedication with $875 \mathrm{mg}$ amoxycillin-clavulonate potassium (Augmentin, Smith Kline, Brentford, UK) was given one hour before surgery. The patients performed a one-minute rinse with chlorhexidine $0.2 \%$ (Tarodent mouthwash) solution before undergoing the procedure.

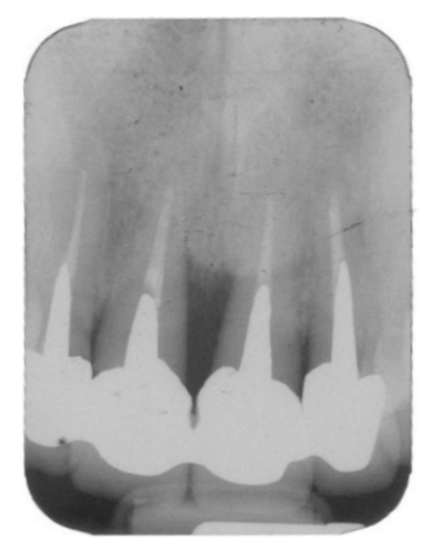

Figure 1. Periapical radiographs of a 37-year-old nonsmoker woman with hopeless 12-22 teeth due to severe bone loss (patient\# 17). 
All surgeries were performed by the same periodontist (R.K.). After appropriate anesthesia of the surgical area, full thickness flaps were elevated, including intrasulcular incisions extending to the midfacial aspect of both distal teeth adjacent to the hopeless ones. Atraumatic extractions were performed with periotomes (Hu-Friedy, Chicago, IL, USA), aiming to preserve the integrity of the socket bony walls. Granulation tissue was removed by means of a spoon curette and a 3-mm diamond burr. The drilling extended to the palatal wall, and bone apical to the extraction sockets was engaged in the osteotomy, always avoiding contact with the buccal wall. Depending on the local bone quality, the last drilling was accomplished with a final drill at least $1 \mathrm{~mm}$ smaller in diameter than the implant width in order to attain the desired stability. Final placement of the implant was implemented with a torque-controlled ratchet. As mentioned before, a torque measurement of $30 \mathrm{Ncm}$ or more was considered stable. Correct 3D implant positioning was considered of pivotal importance in all cases (Figure S1), and the bordering teeth essentially served as a reference for proper implant positioning, as suggested by Buser and colleagues [26]. A minimum distance of $1.5 \mathrm{~mm}$ between the implant shoulder and the neighboring tooth was aimed at in the mesiodistal dimension. In the orofacial dimension, an effort was made to place the buccal neck of the implant 2-3 mm palatal to the buccal contour of the neighboring teeth. The implant's shoulder was flush with the palatal bone: this was $2-3 \mathrm{~mm}$ apical to the cement-enamel junction or to the finishing line of the ceramic crowns of existing neighboring teeth. In all cases, and not related to the socket configuration or defect morphology, allograft material (FDBA-Raptos-Citagenix, Toronto, ON, Canada) was applied in excess over the buccal bone to compensate for the anticipated bone loss and establish a buccal plate of at least $2 \mathrm{~mm}$, as well as to fill the gap between the implant and socket walls (Figure S2). A resorbable collagen membrane (Bio-Gide Geistlisch Pharma AG, Wolhusen, Switzerland) was sited on the increased buccal bone and regenerated socket (Figure S3). The flap was then advanced coronally after a periosteal-releasing incision with a new 15c blade and closely sutured to the palatal flap using Vicryl 4/0 sutures (Figure S4). Transfer adaptation was verified radiographically (Figure 2). Impressions were taken after the insertion of a plastic impression cap by means of the putty-wash one-step technique (Express, 3M. ESPE Dental Products, St. Paul, MN, USA) using the closed tray technique with metal stock trays. The dimensions of the inter-arch relations were recorded.

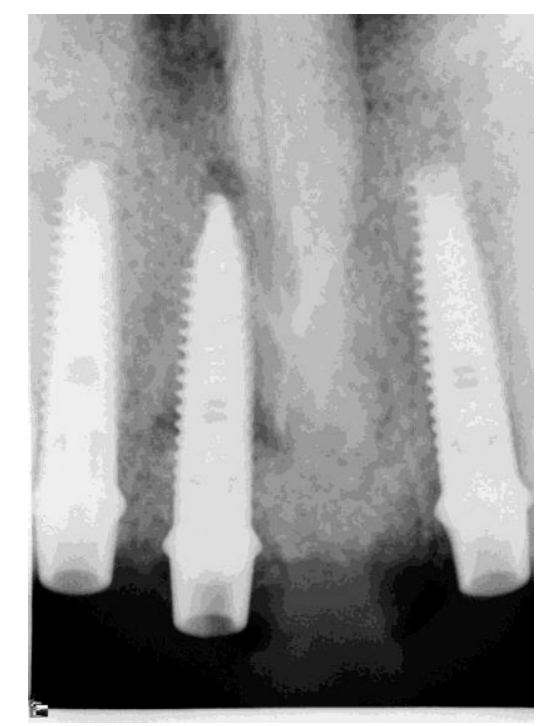

Figure 2. Radiographic verification of transfer adaptation.

\subsubsection{Postoperative Management}

Augmentin was continued for one week (Dalacin $150 \mathrm{mg} \times 4$ per day was prescribed for penicillin-sensitive patients), Narocin $275 \mathrm{mg}$ (Teva Pharm) was given for the relief of pain and swelling, and 1-min $0.2 \%$ chlorhexidine mouth rinses were prescribed twice a day for three weeks. 


\subsubsection{Reconstructive Treatment Protocol}

A master model with a silicon image of the marginal gingiva as well as individual abutments and reinforced temporary bridges were prepared within $24-72 \mathrm{~h}$. The temporary bridge was contoured to mirror the removed tooth, with open embrasure spaces aiming to promote complete papilla formation. Transfer abutments were replaced by individual abutments, followed by the adaptation of a prefabricated non-functional acrylic temporary bridge with minimal occlusal contacts in intercuspal position [IC] but not contacts in protrusive and lateral movements (Figure 3). Implants were considered successful if they fulfilled the criteria of Alberktsson and colleagues [43]. The final zirconia or ceramic bridge restorations were performed six months after implant placement. The final bridge was designed to permit interproximal cleaning (i.e., no attempt was made to fill interproximal spaces with ceramics).

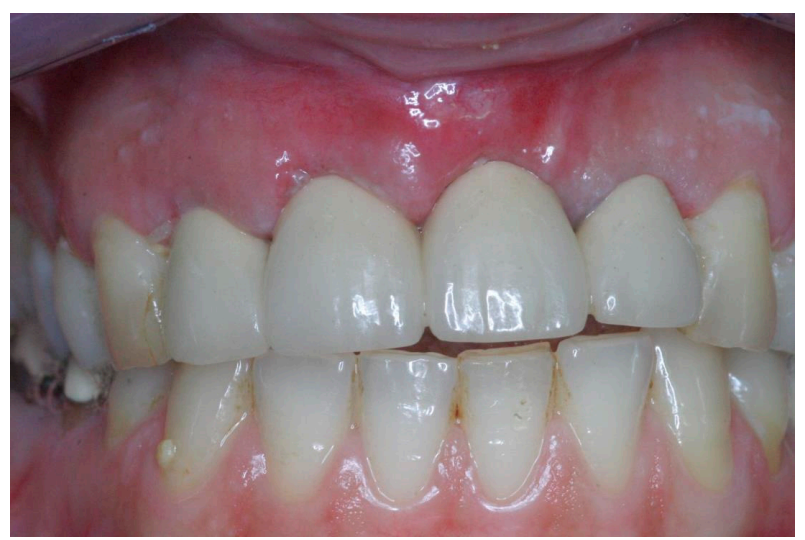

Figure 3. Pre-fabricated non-functional metallic re-enforced acrylic temporary bridge placed $48 \mathrm{~h}$ after implant placement.

Either a screw-type sandblasted and acid-etched surface bone level titanium implant (Lance, MIS, Bar-Lev Industrial Zone Carmiel, Israel) or a conical type of implant (Seven, MIS Bar-Lev Industrial Zone) was used in this study. Six months following implant placement and after removal of the temporary abutments, the adaptation of transfers, and the acquisition of radiographic verification of transfer adaptation, a final impression was taken using a putty and silicone wash (Express, 3M) with the same closed tray technique in metal stock trays. A master model was prepared, and the dimensions of the inter-arch relations were recorded. Abutments were connected, and the fit of the metal or zirconia base framework was tested at the following appointment (Figure 4). The permanent unit's porcelain fused-to-metal (PFM) fixed partial denture or zirconia bridges were cemented after occlusal adjustment and glazing (Figure 5) with temporary cement (Temp-Bond Kerr Corporation, West Collins Orange, CA, USA).

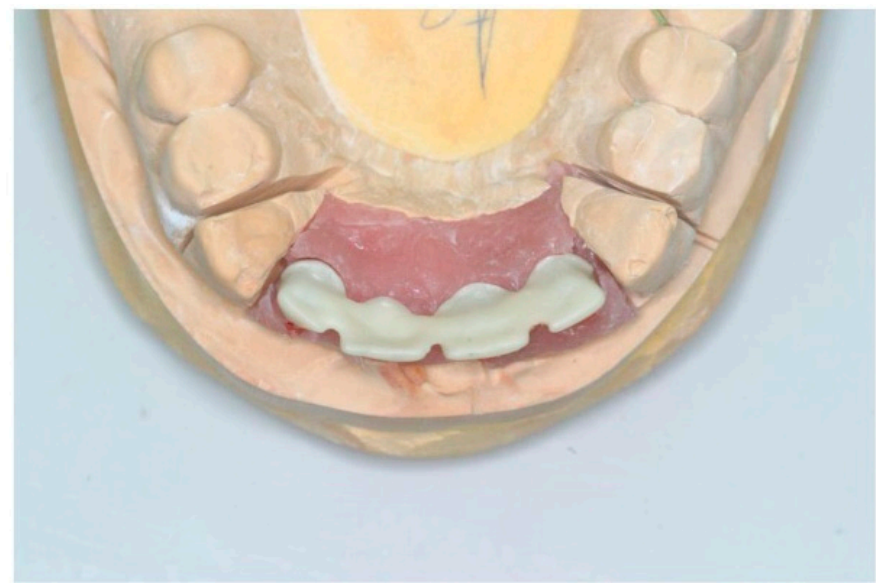

Figure 4. The zirconia base framework. 


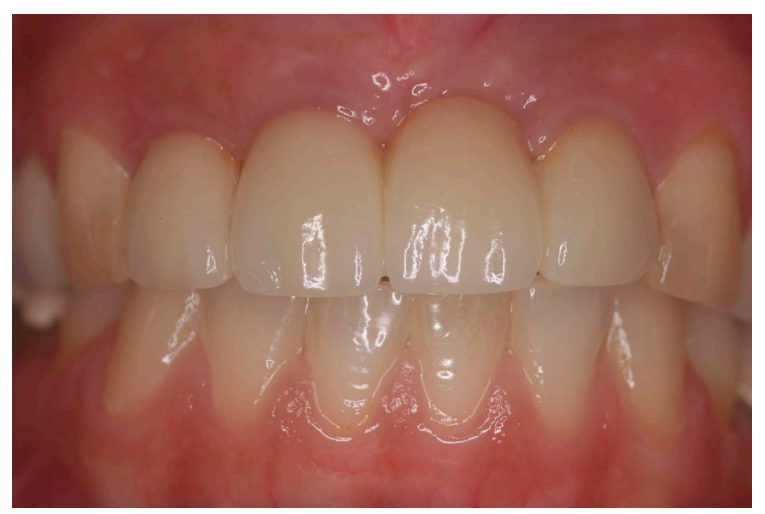

Figure 5. Fixed partial zirconia bridges. The mesial and distal papillae were present six months after implant placement.

\subsection{Clinical Follow-Up Examinations}

The patients underwent clinical examinations at one, two, and four weeks and at three, six, and 12 months postoperatively, and annually thereafter. Supervised dental hygienists performed periodic maintenance examinations. The patients received individualized oral hygiene instructions and were seen and treated when necessary or at least once every 3-6 months.

\subsection{Esthetic Assessment}

The principal investigator (R.K.) followed up with all the study patients at three, six, and 12 months postoperatively, and then annually. In addition, each patient was examined, and frontal photographs were taken (Canon EOS $650 \mathrm{D}$, Tokyo, Japan) with a $100 \mathrm{~mm}$ Canon macro lens and a ring flash, 12 months after the final bridge was adapted (Figures 6-8). The photograph was centered slightly superior to the occlusal plane at the contact region of the teeth for subsequent analysis. The presence or absence of the interproximal papilla was determined as follows: it was deemed missing if a space was visible apical to the contact point and present if tissue filled the embrasure space. Recession was defined as exposure of the metallic collar of the abutment.

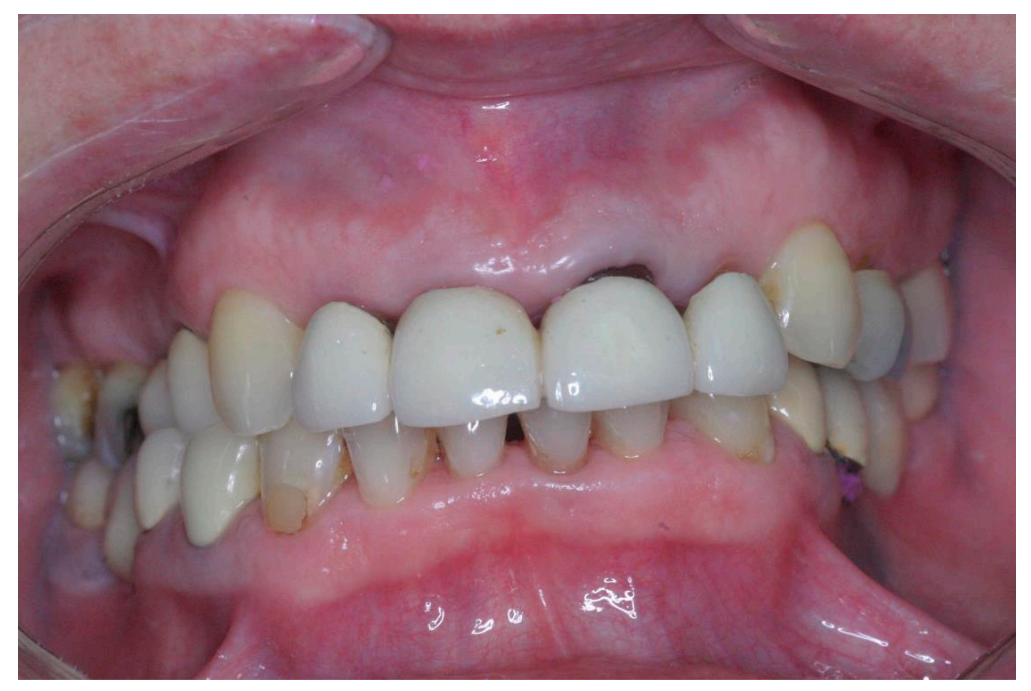

Figure 6. Sixty-year-old nonsmoking woman with hopeless 12-22 teeth due to severe carious lesions (patient \#29). 


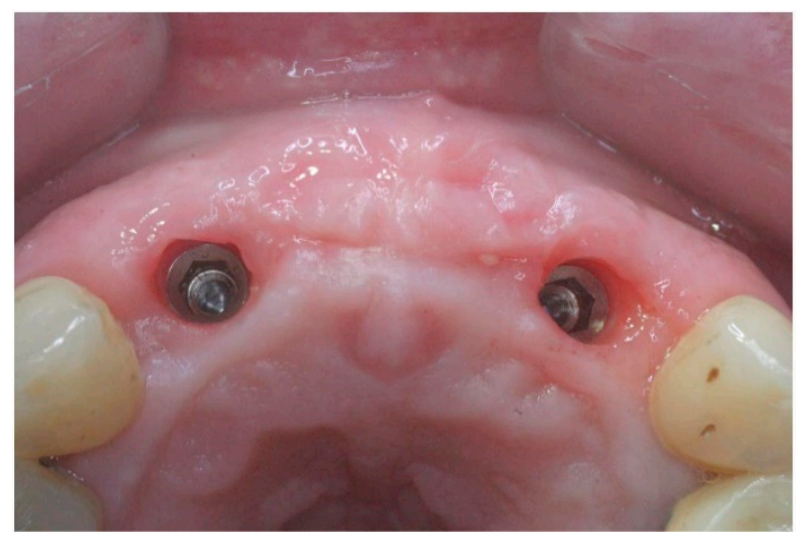

Figure 7. Occlusal view of healthy augmented soft tissue with keratinized sulcular epithelium six months after implant placement and immediate restoration (an FDBA exfoliated graft particle mesial to the left implant is shown) (patient \#29).

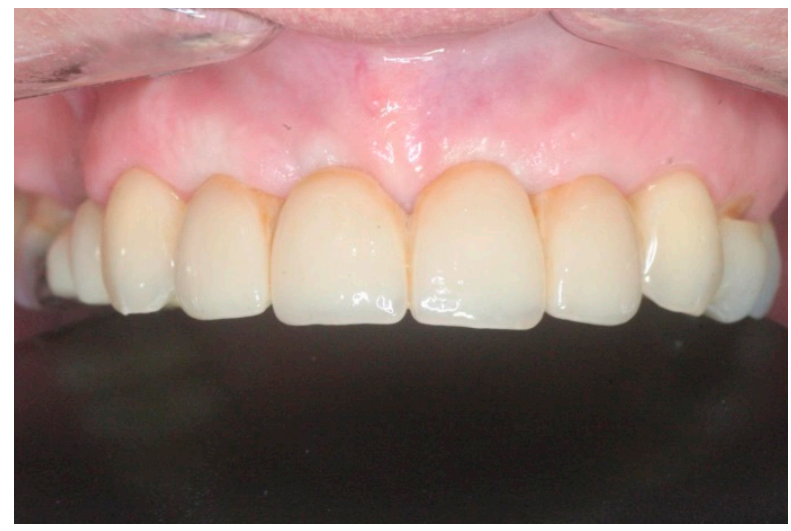

Figure 8. Fixed partial zirconia bridges (patient \#29).

\subsection{Follow-Up and Criteria for Success}

The patients were seen as part of their routine annual recall program 1-7 years after prosthetic bridge installation. They underwent a clinical examination, and non-standardized radiographs were taken with a paralleling device (Figure 9). The distance between the mesial and distal alveolar bone crest and the implant shoulder (First Bone-to-Implant Contact-DIB) was digitally measured using computerized dental radiography (Schick Technologies, Long Island, NY, USA), based on parallel periapical X-rays. Radiographic distortion was calculated by dividing the radiographic implant length by the actual one. One experienced examiner (AWM) who was not involved in the surgical or prosthetic treatment of the patient performed the radiographic readings.
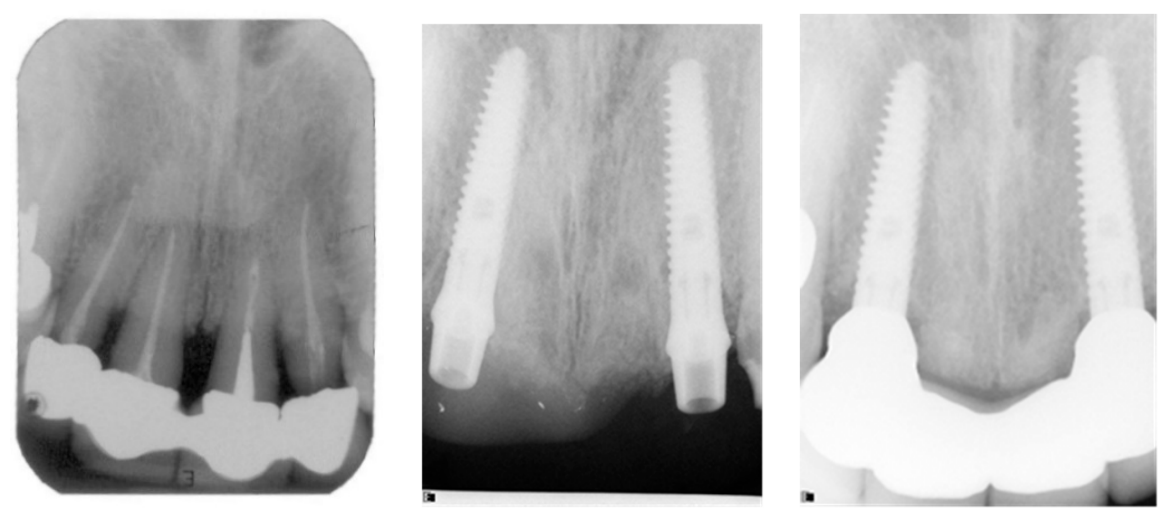

Figure 9. Radiographs taken before treatment, at transfer verification, and 40 months after bridge installation. (patient No. 29). 


\subsection{Statistical Analysis}

Statistical analysis was performed with SPSS 20.0 statistical analysis software (SPSS Inc., Chicago, IL, USA). Due to the relatively small sample size of patients diagnosed with mild chronic periodontitis and gingivitis, the periodontal diagnoses were divided into one group that consisted of gingivitis and mild chronic periodontitis and a second group that consisted of advanced chronic and aggressive periodontitis. Comparisons of mesial and distal marginal bone loss and esthetic parameters (i.e., mesial and distal papillae and recession) between these groups and between the reasons for extractions (periodontitis/caries) were done using the independent Student's $t$-test for numerical variables and the chi-square test or the Fisher Exact test for categorical variables. A $p$-value $<0.05$ was considered the threshold for statistical significance.

\section{Results}

The study population included 39 patients (18 males and 21 females) aged 24 to 85 years (mean $58.3 \pm 13.4$ years) who underwent simultaneous extractions, had immediate implant installation, and underwent guided bone regeneration procedures (Table 1). A total of 118 implants were placed. The mean follow-up period was $32.2 \pm 18$ months (range: $12-84$ months). Twenty-eight (72\%) patients were diagnosed as having chronic advanced adult or aggressive periodontitis, and $11(28 \%)$ were diagnosed with gingivitis and/or mild adult chronic periodontitis (Table 2). The teeth were extracted due to periodontal disease in 20 patients (51\%), severe carious lesions in $18(46 \%)$, and external root resorptions in one $(3 \%)$. The relevant characteristics of the study group (gender, smoking status, and site of each implant) are presented in Table 1. The implant diameter varied between $3.3 \mathrm{~mm}$ and $5 \mathrm{~mm}$ (mean $3.78 \pm 0.42 \mathrm{~mm}$ ), and the implant length varied between $11.5 \mathrm{~mm}$ and $16 \mathrm{~mm}$ (mean $15.17 \pm 1.35 \mathrm{~mm}$ ). Thirty-four patients $(87 \%)$ were non-smokers and five $(13 \%)$ were light smokers.

Table 1. Patients, smoking status, and sites, of implants.

\begin{tabular}{ccc}
\hline Patients Features \& Implant Sites & Number & $\%$ \\
\hline Gender & & \\
\hline Female & 21 & 53 \\
Male & 18 & 47 \\
\hline Smokers & & \\
\hline$<10$ cigarettes per day & 5 & 13 \\
Non-smokers & 34 & 87 \\
\hline Implant site, maxilla & & \\
Central incisor & 25 & 21 \\
Lateral incisor & 42 & 36 \\
Canine & 11 & 9 \\
First premolar & 14 & 12 \\
Second premolar & 17 & 14 \\
First molar & 9 & 8 \\
\hline
\end{tabular}

Table 2. Periodontal diagnosis.

\begin{tabular}{cc}
\hline Periodontal Diagnosis & Number (\%) \\
\hline Gingivitis & $4(10)$ \\
Chronic mild adult periodontitis & $7(18)$ \\
Chronic advanced adult & $23(59)$ \\
periodontitis & $5(13)$ \\
Aggressive periodontitis & \\
\hline
\end{tabular}




\section{Radiographic Findings/DIB Values}

At the time of data collection (2013), 1-7 years after prosthetic bridge installation, no implants had been lost, and 106 out of the 118 (89.8\%) implants were successful (Table 3) according to the criteria set by Alberktsson and colleagues in 1986 [43]. Specifically, there was no more than $1.5 \mathrm{~mm}$ of bone loss for the first year and an additional $0.2 \mathrm{~mm}$ for each successive year. Twelve implants had lost more than $1.5 \mathrm{~mm}$ of bone, three of them in the same patient, who was a 64-year-old male and light smoker (these were defined as survival). There was a mean mesial bone loss of $1.19 \pm 0.63 \mathrm{~mm}$ (range: $0.56-1.82 \mathrm{~mm}$ ) and a mean distal bone loss of $1.18 \pm 0.64 \mathrm{~mm}$ (range: $0.54-1.82 \mathrm{~mm}$ ) for the whole group during the follow-up period. The mean marginal bone loss per patient at the time of data collection was $1.16 \pm 0.46$ and $0.58 \pm 0.37$ per year (Table 3). The marginal bone loss in patients that needed extractions due to periodontitis was higher compared to those in which extractions were performed due to caries. The mean loss was $1.37 \mathrm{~mm}$ vs. $1.01 \mathrm{~mm}$, respectively, for the mesial bone and $1.37 \mathrm{~mm}$ and $0.99 \mathrm{~mm}$, respectively, for the distal bone ( $p=0.001 \mathrm{for}$ each). The severity of the periodontal disease at baseline affected only the numerical variables (marginal bone loss) but did not affect the aesthetic parameters (papillae and recessions).

Table 3. Marginal bone loss in 39 patients (118 implants).

\begin{tabular}{|c|c|c|c|c|c|c|c|}
\hline Patient NO. & Age & Gender & Smoker & $\begin{array}{l}\text { Follow-Up } \\
\text { (Month) }\end{array}$ & $\underset{(n)}{\text { Implants }}$ & $\begin{array}{c}\text { Bone } \\
\text { Loss/Patient }\end{array}$ & $\mathrm{mm} /$ Year \\
\hline 1 & 56 & F & light & 84 & 4 & 1.05 & 0.15 \\
\hline 2 & 53 & F & no & 36 & 3 & 2.02 & 0.67 \\
\hline 3 & 74 & M & light & 72 & 5 & 2.74 & 0.46 \\
\hline 4 & 85 & $\mathrm{~F}$ & no & 36 & 2 & 1.40 & 0.47 \\
\hline 5 & 40 & M & no & 12 & 2 & 0.85 & 0.85 \\
\hline 6 & 24 & M & no & 60 & 2 & 1.25 & 0.25 \\
\hline 7 & 60 & M & no & 54 & 4 & 1.13 & 0.28 \\
\hline 8 & 44 & $\mathrm{~F}$ & no & 36 & 2 & 1.55 & 0.52 \\
\hline 9 & 56 & M & no & 60 & 4 & 1.50 & 0.30 \\
\hline 10 & 62 & $\mathrm{~F}$ & light & 30 & 4 & 0.96 & 0.39 \\
\hline 11 & 56 & F & no & 12 & 3 & 0.65 & 0.65 \\
\hline 12 & 56 & F & no & 36 & 4 & 1.24 & 0.41 \\
\hline 13 & 47 & F & no & 24 & 3 & 1.77 & 0.88 \\
\hline 14 & 58 & F & no & 24 & 2 & 0.83 & 0.41 \\
\hline 15 & 35 & F & light & 40 & 4 & 1.30 & 0.39 \\
\hline 16 & 59 & M & no & 36 & 2 & 0.90 & 0.30 \\
\hline 17 & 37 & $\mathrm{~F}$ & no & 40 & 3 & 1.12 & 0.34 \\
\hline 18 & 63 & M & no & 36 & 5 & 1.07 & 0.36 \\
\hline 19 & 63 & $\mathrm{M}$ & no & 36 & 2 & 0.93 & 0.31 \\
\hline 20 & 46 & M & no & 40 & 3 & 1.07 & 0.32 \\
\hline 21 & 80 & $\mathrm{~F}$ & no & 12 & 2 & 1.25 & 1.25 \\
\hline 22 & 64 & M & light & 24 & 3 & 1.20 & 0.60 \\
\hline 23 & 68 & $\mathrm{~F}$ & no & 36 & 2 & 1.23 & 0.41 \\
\hline 24 & 57 & M & no & 24 & 3 & 1.05 & 0.53 \\
\hline 25 & 36 & $\mathrm{~F}$ & no & 12 & 4 & 0.65 & 0.65 \\
\hline 26 & 49 & F & no & 12 & 2 & 0.80 & 0.80 \\
\hline 27 & 67 & F & no & 24 & 2 & 0.88 & 0.44 \\
\hline 28 & 55 & M & no & 12 & 2 & 0.90 & 0.90 \\
\hline 29 & 60 & $\mathrm{~F}$ & no & 24 & 2 & 0.73 & 0.36 \\
\hline 30 & 68 & M & no & 48 & 6 & 1.10 & 0.28 \\
\hline 31 & 53 & M & no & 48 & 4 & 1.03 & 0.26 \\
\hline 32 & 75 & $\mathrm{~F}$ & no & 12 & 2 & 1.93 & 1.93 \\
\hline 33 & 74 & F & no & 24 & 4 & 2.03 & 1.01 \\
\hline 34 & 67 & M & no & 48 & 3 & 0.82 & 0.20 \\
\hline 35 & 83 & M & no & 12 & 4 & 0.71 & 0.71 \\
\hline 36 & 69 & $\mathrm{M}$ & no & 12 & 2 & 0.50 & 0.50 \\
\hline 37 & 61 & M & no & 12 & 2 & 0.60 & 0.60 \\
\hline 38 & 59 & $\mathrm{~F}$ & no & 12 & 4 & 0.81 & 0.81 \\
\hline 39 & 55 & $\mathrm{~F}$ & no & 48 & 2 & 1.55 & 1.55 \\
\hline Average \pm SD & $58.3 \pm 13.4$ & - & - & $32.3 \pm 18.2$ & - & $1.16 \pm 0.46$ & $0.58 \pm 0.37$ \\
\hline
\end{tabular}




\section{Aesthetic Parameters}

The mesial papillae were present in 83/118 implants (70.3\%), while the distal papillae were present in 76/118 (64.4\%). The cervical metallic part of the abutment was exposed in 16 out of 118 $(13.5 \%)$ implants. There was a higher ratio of recessions and missing papillae among patients whose extractions were performed due to periodontal reasons (Table 4).

Table 4. Treatment outcomes per implant level. A comparison according to the reason for extractions between 61 implants in patients with periodontitis and 55 implants in patients with a caries etiology.

\begin{tabular}{cccc}
\hline Outcomes & $\begin{array}{c}\text { Extraction Due to Periodontitis } \\
\boldsymbol{n = 6 1}\end{array}$ & $\begin{array}{c}\text { Extraction Due to Caries } \\
\boldsymbol{n = 5 5}\end{array}$ & $\boldsymbol{p}$-Value \\
\hline Esthetic outcomes & & & \\
\hline Mesial papilla & $37(60.7 \%)$ & $44(80 \%)$ & 0.05 \\
Distal papilla & $33(54.1 \%)$ & $41(74.5 \%)$ & 0.04 \\
Recession & $13(21.3 \%)$ & $3(5.5 \%)$ & 0.04 \\
\hline Radiographic data (mm), mean \pm SD & & & \\
\hline Mesial bone loss & $1.37 \pm 0.8$ & $1.01 \pm 0.3$ & 0.001 \\
Distal bone loss & $1.37 \pm 0.8$ & $0.99 \pm 0.3$ & 0.001 \\
Bone loss/implant & $1.37 \pm 0.8$ & $1 \pm 0.3$ & 0.001 \\
\hline
\end{tabular}

A comparison of esthetic treatment outcomes between patients who had extractions due to a periodontal etiology and caries is shown in Table 4. All outcome-related variables were worse in patients who underwent the extraction due to a periodontal etiology compared to those treated for a caries etiology (Table 4).

\section{Technical Complications}

The main technical complications were loosening of provisional bridges. Ten bridges $(25.6 \%)$ were re-cemented with temporary cement and 18 abutments (15\%) were re-tightened without any further complications. Five definitive bridges lost retention in five patients. Finally, all the bridges were re-cemented with harder temporary cement (Cem Implant, Ivoclar Vivadent, Schaan, Liechtenstein). There were no ceramic fractures.

\section{Discussion}

In the present study we found a $100 \%$ cumulative survival rate and an approximately $90 \%$ success rate for the immediate restoration procedure in a cohort of 39 patients (118 implants) followed-up for a mean of 32.3 months. We detected a relatively low mean marginal bone loss per implant $(1.19 \pm 0.63 \mathrm{~mm}) 12-84$ months after implant placement. These figures are comparable to the mean marginal bone loss observed in delayed as well as immediately loaded implants [15,44-47]. This outcome is probably the result of bone substitute grafting, which enhances bone fill and augments the buccal bony plate $[43,48]$, as well as to the good compliance of the patients.

The present encouraging data on marginal bone loss of combined GBR and multiple implant placements are comparable to those recently reported for single tooth replacement using a similar GBR protocol $[49,50]$. The survival rate of the current study patients, in whom the extractions were mainly due to periodontal reasons, reflects that of Testori and colleagues [51], who reported a $98.8 \%$ survival rate at 12 months after implant placement rehabilitated with a full-arch prosthesis supported by six implants. Our results are also comparable with Malo and colleagues' report [52] of a mean $1.2 \pm 0.9 \mathrm{~mm}$ bone loss one year after implant placement in periodontally compromised sites. Similar to their study findings, most of the socket walls in the current study participants were compromised in vertical and/or horizontal dimensions, mainly due to previous periodontal disease.

Slightly over one-half (51\%) of the teeth in the present study were extracted due to advanced periodontal disease. The remaining teeth were extracted due to caries including deep horizontal 
fractures of the crown and external resorption, Primary stability of the implant is a key factor for success in the immediate loading approach [10-14]. In the present study, all the implants replaced teeth in regions that are prone-at least theoretically (type 2,3) [14]—-to immediate loading procedures (excluding second and third molar areas) [14]. The threshold value of primary stability was achieved even in those placed in the first molar region due to the palatal bone engagement of the implants that favors osseointegration. This can be achieved by using implants with appropriate macro geometry in combination with an under-preparation of the implant site that takes into consideration the local bone quality [10-12]. Solidarization of the implants with the prosthesis may also contribute to increased stability [10-12].

In the present study, an attempt had been made to minimize the potential collapse of buccal bone by using slow resorbable allograft mineralized material in the space that was created by the dimensional discrepancy between the bony walls of the extraction socket and the body of the implant, commonly described as the "gap". A collagen membrane was used to enhance bone regeneration and reduce the risk of membrane infection in the event of any soft-tissue dehiscence occurring postoperatively $[53,54]$. A recent study [55] demonstrated that facial soft-tissue thickness (labio-palatal) was greater at sites that received bone grafts and provisional restorations compared to sites without either grafts or restorations. Moreover, current thinking in this area of research is that increasing peri-implant soft-tissue thickness increases the color-masking ability and bone stability [56,57]. A possible explanation for the soft-tissue enhancement achieved by using bone grafts may be that particulate graft materials could be incorporated and encapsulated into the peri-implant mucosal soft tissues [58]. These particles may act as a benign foreign body precursor with an asymptomatic enlargement of the gingival margins [58].This increase in volume can create a masking effect that would counteract gray-colored abutments and enhance the esthetic outcome without the use of a sub epithelial connective tissue graft (not used in the present study). In addition, since human studies have shown that $90 \%$ of patients have a buccal bone plate thickness of $1 \mathrm{~mm}$ or less [25], a deliberate overfill above the buccal bone using the same graft materials together with a resorbable collagen membrane was performed in order to achieve a thicker bony plate. That maneuver was intended to maintain long-term aesthetics and success [43], as previously described by the authors in healed sites [48] and in immediately restored implants [49].

Despite those efforts to achieve over-contouring and an enhanced buccal hard-tissue augmentation, exposure of the cervical metallic part of the abutment was observed in 16 patients $(13.5 \%)$, an outcome seen with a higher ratio in patients in whom multiple extractions were performed and in patients where the etiology was periodontal. This recession ratio is lower than that of immediately placed but not restored implants in the aesthetic zone, yielding a significant number of sites with soft-tissue recession (approximately 40\%) [27,59]. There are no comparable data for immediately placed and immediately loaded implants.

A variety of factors influences the presence or absence of the papilla. These factors include the anatomy of the neighboring tooth/implant [36], the distance between implant and the neighboring teeth and to the adjacent implant [33], the implant system [38], the distance between the contact point and bone level [34], as well as the timing of implant placement and the use of a provisional reconstruction [23]. From a clinical point of view, the vertical distance between the alveolar crest and the contact point of the adjacent tooth appears to be the factor that has the most significant influence upon the height of the papilla between natural teeth [60]. The present study results on the incidence of mesial papilla in $70 \%$ of the cases and of distal papilla in $64 \%$ of the cases is not surprising since the interdental bone peak resorbs following extraction of adjacent teeth and when the attachment level in periodontal patients is compromised [60]. The present data on the presence of interdental papillae are in accordance with those of an earlier report on the replacement of single teeth with compromised buccal bone, in which it was stated that the accomplishment of complete papillae was not predictable [49]. 
The limitations of the present study are the lack of a similarly treated control group, the use of X-ray positioning without a personalized jig and the relatively small number of patients in the study group.

\section{Conclusions}

The present study examines the aesthetic performance and implant survival of immediately placed multiple implants that are restored concomitantly with hard-tissue augmentation in partially edentulous maxillary patients. The presented surgical approach successfully achieved immediate aesthetic appearance, function, and stability of the surrounding tissues. As verified by radiographic parameters, the cumulative survival rate for the immediate restoration procedure in the present study was $100 \%$. Potential technical solutions are presented, including palatal placement and temporary acrylic bridge support of papillae and buccal gingiva. Moreover, evidence is provided to attest to the potential efficacy of small particulate FDBA graft material and native collagen membranes to enable successful wound healing in a transgingival environment.

Supplementary Materials: The following are available online at www.mdpi.com/2076-3417/8/3/377/s1, Figure S1: The buccal neck of the implant is at least $2 \mathrm{~mm}$ palatal to the buccal contour of the neighboring teeth. The neck of the implant was flush with the palatal bone in an apico-coronal direction. Figure S2: Allograft material was applied in the residual gap and above the buccal wall. Figure S3: A resorbable collagen membrane was applied after adaptation of an appropriate transfer abutment. Figure S4: A coronally positioned flap was performed after a periosteal releasing incision.

Author Contributions: Roni Kolerman: Concept/design, implant installation, data collection and analysis, interpretation, writing the manuscript. Nissan Joseph: Concept/design, data analysis, critical revision of the article. Eitan Barnea: Concept/design, prosthetic reconstruction of patients, aesthetic assessment. Jose Luis Calvo Guirado: Critical revision of the article. Liat Chaushu: Critical revision of the article. Manar Abu Wasel: Radiographic analysis, data collection. Haim Tal: Concept/design, critical revision of the article.

Conflicts of Interest: The authors declare no conflict of interest.

\section{References}

1. Becker, W.; Becker, B.E. Guided tissue regeneration for implants placed into extraction sockets and for implant dehiscences: Surgical techniques and case report. Int. J. Periodontic Res. Dent. 1990, 10, 376-391.

2. Becker, W.; Becker, B.E.; Handelsman, M.; Ochsenbein, C.; Albrektsson, T. Guided tissue regeneration for implants placed into extraction sockets: A study in dogs. J. Periodontol. 1991, 62, 703-709. [CrossRef] [PubMed]

3. Gelb, D.A. Immediate implant surgery: Three years retrospective evaluation of 50 consecutive cases. Int. J. Oral Maxillofac. Implants 1993, 8, 388-399. [PubMed]

4. Gomez-Roman, G.; Kruppenbacher, M.; Weber, H.; Schulte, W. Immediate postextraction implant placement with root analog steeped implants: Surgical procedure and statistical outcome after 6 years. Int. J. Oral Maxillofac. Implants 2001, 16, 503-513. [PubMed]

5. Polizzi, G.; Grunder, U.; Goené, R.; Hatano, N.; Henry, P.; Jackson, W.J.; Kawamura, K.; Renouard, F.; Rosenberg, R.; Triplett, G.; et al. Immediate and delayed implant placement into extraction sockets: A 5-year report. Clin. Implant Dent. Relat. Res. 2000, 2, 93-99. [CrossRef] [PubMed]

6. Tolman, D.E.; Keller, E.E. Endosseous implant placement immediately following dental extraction and alveoloplasty: Preliminary report with 6-year follow up. Int. J. Oral Maxillofac. Implants 1991, 6, $24-28$. [CrossRef] [PubMed]

7. Randow, K.; Ericsson, I.; Nilner, K.; Petersson, A.; Glantz, P.O. Immediate functional loading of Brånemark dental implants. An 18-month clinical follow-up study. Clin. Implant Dent. Relat. Res. 1990, 10, 8-15.

8. Salama, H.; Rose, L.F.; Salama, M.; Betts, N.J. Immediate loading of bilaterally splinted titanium root- form implants in fixed prosthodontics-A technique reexamined: Two case reports. Int. J. Periodontic Res. Dent. 1995, 15, 344-361.

9. Schnitman, P.A.; Whorle, P.S.; Rubenstein, J.E.; DaSilva, J.D.; Wang, N.H. Ten-year results for Brånemark implants immediately loaded with fixed prostheses at implant placement. Int. J. Oral Maxillofac. Implants 1997, 12, 495-503. [PubMed] 
10. Tarnow, D.P.; Emtiaz, S.; Classi, A. Immediate loading of threaded implants at stage 1 surgery in edentulous Arches: Ten consecutive case reports with 1- to 5-year data. Int. J. Oral Maxillofac. Implants 1997, 12, 319-324. [PubMed]

11. Bergkvist, G.; Sahlholm, S.; Karlsson, U.; Nilner, K.; Lindh, C. Immediately loaded implants supporting fixed prostheses in the edentulous maxilla: A preliminary clinical and radiologic report. Int. J. Oral Maxillofac. Implants 2005, 20, 399-405. [CrossRef] [PubMed]

12. Degidi, M.; Piatteli, A.; Felice, P.; Carinci, F. Immediate functional loading of edentulous maxilla: A 5-year retrospective study of 388 titanium implants. J. Periodontol. 2005, 76, 1016-1024. [CrossRef] [PubMed]

13. Ibanez, J.C.; Tahhan, M.J.; Zamar, J.A.; Menendez, A.B.; Juaneda, A.M.; Zamar, N.J.; Monqaut, J.L. Immediate occlusal loading of double acid-etched surface titanium implants in 41 consecutive full-arch cases in the mandible and maxilla: 6 to 74-month results. J. Periodontol. 2005, 76, 1972-1981. [CrossRef] [PubMed]

14. Grütter, L.; Belser, U.C. Implant loading protocols for the partially edentulous esthetic zone. Int. J. Oral Maxillofac. Implants 2009, 24, 169-179. [PubMed]

15. Andersen, E.; Haanaes, H.R.; Knusten, M. Immediate loading of single-tooth ITI implants in the anterior maxilla: A prospective 5-year pilot study. Clin. Oral Implants Res. 2002, 13, 281-287. [CrossRef] [PubMed]

16. Chausu, G.; Chausu, S.; Tzohar, A.; Dayan, D. Immediate loading of single tooth implants: Immediate versus non-immediate implantation. A clinical report. Int. J. Oral Maxillofac. Implants 2001, 16, 267-272.

17. Cooper, L.; Felton, D.A.; Kugelberg, C.F.; Ellner, S.; Chaffee, N.; Molina, A.L.; Moriarty, J.D.; Paquette, D.; Palmqvist, U. A multicenter 12-month evaluation of single-tooth implants restored 3 weeks after 1-stage surgery. Int. J. Oral Maxillofac. Implants 2001, 16, 182-192. [PubMed]

18. Ericcsson, I.; Nilson, H.; Lindh, T.; Nilner, K.; Randow, K. Immediate functional loading of Brånemark single tooth implants. An 18 months' clinical pilot follow-up study. Clin. Oral Implants Res. 2000, 11, 26-33. [CrossRef]

19. Grunder, U. Stability of the mucosal topography around single-tooth implants and adjacent teeth: 1-year results. Int. J. Periodontics Res. Dent. 2000, 20, 11-17.

20. Lindeboom, J.A.; Tjiook, Y.; Kroon, F.H. Immediate placement of implants in periapical infected sites: A prospective randomized study in 50 patients. Oral Surg. Oral Med. Oral Pathol. Oral Radiol. Endod. 2006, 101, 705-710. [CrossRef] [PubMed]

21. Norton, M.R. A short-term clinical evaluation of immediately restored maxillary TiOblast single-tooth implants. Int. J. Oral Maxillofac. Implants 2004, 19, 274-281. [PubMed]

22. Kois, J.C. Predictable single tooth peri-implant esthetic: Five diagnostic keys. Compend. Contin. Educ. Dent. 2001, 22, 199-206. [PubMed]

23. Saito, H.; Chu, S.J.; Reynolds, M.A.; Tarnow, D.P. Provisional restorations used in immediate implant placement provide a platform to promote peri-implant soft tissue healing: A pilot study. Int. J. Periodontics Res. Dent. 2016, 36, 47-52. [CrossRef] [PubMed]

24. Esposito, M.; Grusovin, M.G.; Polyzos, I.P.; Felice, P.; Worthington, H.V. Timing of implant placement after tooth extraction: Immediate, immediate-delayed or delayed implants? A Cochrane systematic review. Eur. J. Oral Implantol. 2010, 3, 189-205. [PubMed]

25. Huynh-Ba, G.; Pjetursson, B.E.; Sanz, M.; Cecchinato, D.; Ferrus, J.; Lindhe, J.; Lang, N.P. Analysis of the socket bone wall dimensions in the upper maxilla in relation to immediate implant placement. Clin. Oral Implants Res. 2010, 21, 37-42. [CrossRef] [PubMed]

26. Buser, D.; Martin, W.; Belser, U.C. Optimizing esthetics for implant restorations in the anterior maxilla: Anatomic and surgical considerations. Int. J. Oral Maxillofac. Implants 2004, 19, 43-61. [PubMed]

27. Evans, C.D.; Chen, S.T. Esthetic outcomes of immediate implant placements. Clin. Oral Implants Res. 2008, 19, 73-80. [CrossRef] [PubMed]

28. Zitzmann, N.U.; Scharer, P.; Marinello, C.P. Long-term results of implants treated with guided bone regeneration: A 5-year prospective study. Int. J. Oral Maxillofac. Implants 2001, 16, 355-366. [PubMed]

29. Chen, S.T.; Darby, I.B.; Adams, G.G.; Reynolds, E.C. A prospective clinical study of bone augmentation techniques at immediate implants. Clin. Oral Implants Res. 2005, 16, 176-184. [CrossRef] [PubMed]

30. Araujo, M.G.; Lindhe, J. Dimensional ridge alterations following tooth extraction. An experimental study in the dog. J. Clin. Periodontol. 2005, 32, 212-218. [CrossRef] [PubMed]

31. Grunder, U.; Gracis, S.; Capelli, M. Influence of the 3-D bone-to-implant relationship on esthetics. Int. J. Periodontics Res. Dent. 2005, 25, 113-119. 
32. Cosyn, J.; Eghbali, A.; De Bruyn, H.; Collys, K.; Cleymaet, R.; De Rouck, T. Immediate single-tooth implants in the anterior maxilla: 3-year results of a case series on hard and soft tissue response and aesthetics. J. Clin. Periodontol. 2011, 38, 746-753. [CrossRef] [PubMed]

33. Schropp, L.; Isidor, F. Papilla dimension and soft tissue level after early vs. delayed placement of single-tooth implants: 10-year results from a randomized controlled clinical trial. Clin. Oral Implants Res. 2015, 26, 278-286. [CrossRef] [PubMed]

34. Tarnow, D.; Elian, N.; Fletcher, P.; Froum, S.; Magner, A.; Cho, S.C.; Salama, M.; Salama, H.; Garber, D.A. Vertical distance from the crest of bone to the height of the interproximal papilla between adjacent implants. J. Periodontol. 2003, 74, 1785-1788. [CrossRef] [PubMed]

35. Cosyn, J.; Raes, M.; Packet, M.; Cleymaet, R.; De Bruyn, H. Disparity in embrasure fill and papilla height between tooth and implant-borne fixed restorations in the anterior maxilla: A cross-sectional study. J. Clin. Periodontol. 2013, 40, 728-733. [CrossRef] [PubMed]

36. Esposito, M.; Hirsch, J.M.; Lekholm, U.; Thomsen, P. Biological factors contributing to failures of osseointegrated oral implants. (I). Success criteria and epidemiology. Eur. J. Oral Sci. 1998, 106, 527-551. [CrossRef] [PubMed]

37. Esposito, M.; Hirsch, J.M.; Lekholm, U.; Thomsen, P. Biological factors contributing to failures of osseointegrated oral implants. (II). Etiopathogenesis. Eur. J. Oral Sci. 1998, 106, 721-764. [CrossRef] [PubMed]

38. Tarnow, D.P.; Cho, S.C.; Wallace, S.S. The effect of inter-implant distance on the height of inter-implant bone crest. J. Periodontol. 2000, 71, 546-549. [CrossRef] [PubMed]

39. Esposito, M.; Ekestubbe, A.; Grondahl, K. Radiological evaluation of marginal bone loss at tooth surfaces facing single Brånemark implants. Clin. Oral Implants Res. 1993, 4, 151-157. [CrossRef] [PubMed]

40. Cardaropoli, G.; Lekholm, U.; Wennstrom, J.L. Tissue alterations at implant-supported single-tooth replacement: A 1-year prospective clinical study. Clin. Oral Implants Res. 2006, 17, 165-171. [CrossRef] [PubMed]

41. Spray, J.R.; Black, C.G.; Morris, H.F.; Ochi, S. The influence of bone thickness on facial marginal bone response: Stage 1 placement through stage 2 uncovering. Ann. Periodontol. 2000, 5, 119-128. [CrossRef] [PubMed]

42. O'Leary, T.J.; Drake, R.B.; Naylor, J.E. The plaque control record. J. Periodontol. 1972, 43, 38. [CrossRef] [PubMed]

43. Alberktsson, T.; Zarb, G.; Wotthington, P.; Eriksson, R.A. The long-term efficacy of currently used dental implants: A review and proposed criteria of success. Int. J. Oral Maxillofac. Implants 1986, 1, 11-25.

44. Penarrocha-Diago, M.A.; Flichy-Fernandez, A.J.; AlonsoGonzalez, R.; Penarrocha-Oltra, D.; Balaguer-Martınez, J.; Penarrocha-Diago, M. Influence of implant neck design and implant-abutment connection type on peri-implant health. Radiological study. Clin. Oral Implants Res. 2013, 24, 1192-1200. [CrossRef] [PubMed]

45. Enkling, N.; Johren, P.; Katsoulis, J.; Bayer, S.; Jervoe-Storm, P.M.; Mericske-Stern, R.; Jepsen, S. Influence of platform switching on bone-level alterations: A three-year randomized clinical trial. J. Dent. Res. 2013, 92, 139s-145s. [CrossRef] [PubMed]

46. Vogl, S.; Stopper, M.; Hof, M.; Wegscheider, W.A.; Lorenzoni, M. Immediate occlusal versus non-occlusal loading of implants: A randomized clinical pilot study. Clin. Implant Dent. Relat. Res. 2015, 17, 589-597. [CrossRef] [PubMed]

47. Chrcanovic, B.R.; Albrektsson, T.; Wennerberg, A. Immediately loaded non-submerged versus delayed loaded submerged dental implants: A meta-analysis. Int. J. Oral Maxillofac. Surg. 2015, 44, 493-506. [CrossRef] [PubMed]

48. Kolerman, R.; Nissan, J.; Tal, H. Combined osteotome induced ridge expansion and guided bone regeneration with simultaneous implant placement: A biometric study. Clin. Implant Dent. Relat. Res. 2013, 25, 1-14. [CrossRef] [PubMed]

49. Kolerman, R.; Nissan, J.; Mijiritsky, E.; Hamoudi, N.; Mangano, C.; Tal, H. Esthetic assessment of immediately restored implants combined with GBR and free connective tissue graft. Clin. Oral Implants Res. 2016, 27, 1414-1422. [CrossRef] [PubMed]

50. Kolerman, R.; Nissan, J.; Rahmanov, A.; Zenziper, E.; Slutzkey, S.; Tal, H. Radiological and biological assessment of immediately restored anterior maxillary implants combined with GBR and free connective tissue graft. Clin. Implant Dent. Relat. Res. 2016, 18, 1142-1152. [CrossRef] [PubMed] 
51. Testori, T.; Del Fabbro, M.; Capelli, M.; Zuffetti, F.; Francetti, L.; Weinstein, R.L. Immediate occlusal loading and tilted implants for the rehabilitation of the atrophic edentulous maxilla: 1-year interim results of a multicenter prospective study. Clin. Oral Implants Res. 2008, 19, 227-232. [CrossRef] [PubMed]

52. Maló, P.; Nobre, M.; Rangert, B. Implants placed in immediate function in periodontally compromised sites: A five-year retrospective and one-year prospective study. J. Prosthet. Dent. 2007, 97, 86-95. [CrossRef]

53. Stavropoulos, F.; Dahlin, C.; Ruskin, J.D.; Johansson, C.A. Comparative study of barrier membranes as graft protectors in the treatment of localized bone defects. An experimental study in a canine model. Clin. Oral Implants Res. 2004, 15, 435-442. [CrossRef] [PubMed]

54. Buser, D.; Dula, K.; Lang, N.P.; Nyman, S. Long-term stability of osseointegrated implants in bone regenerated with the membrane technique. 5-year results of a prospective study with 12 implants. Clin. Oral Implants Res. 1996, 7, 175-183. [CrossRef] [PubMed]

55. Chu, S.J.; Salama, M.A.; Garber, D.A.; Salama, H.; Sarnachiaro, G.O.; Sarnachiaro, E.; Gotta, S.L.; Reynolds, M.A.; Saito, H.; Tarnow, D.P. Flapless postextraction socket implant placement, Part 2: The effects of bone grafting and provisional restoration on peri-implant soft tissue height and thickness-A retrospective study. Int. J. Periodontics Res. Dent. 2015, 35, 803-809. [CrossRef] [PubMed]

56. Linkevicius, T.; Apse, P.; Grybauskas, S.; Puisys, A. The influence of soft tissue thickness on crestal bone changes around implants: A 1-year prospective controlled clinical trial. Int. J. Oral Maxillofac. Implants 2009, 24, 712-719. [PubMed]

57. Puisys, A.; Linkevicius, T. The influence of mucosal tissue thickening on crestal bone stability around bone-level implants. A prospective controlled clinical trial. Clin. Oral Implants Res. 2015, 26, 123-129. [CrossRef] [PubMed]

58. Araújo, M.G.; Linder, E.; Lindhe, J. Bio-Oss collagen in the buccal gap at immediate implants: A 6-month study in the dog. Clin. Oral Implants Res. 2011, 22, 1-8. [CrossRef] [PubMed]

59. Juodzbalys, G.; Wang, H.L. Soft and hard tissue assessment of immediate implant placement: A case series. Clin. Oral Implants Res. 2007, 18, 237-243. [CrossRef] [PubMed]

60. Tarnow, D.P.; Magner, A.W.; Fletcher, P. The effect of the distance from the contact point to the crest of bone on the presence or absence of the interproximal dental papilla. J. Periodontol. 1992, 63, 995-996. [CrossRef] [PubMed] 